\title{
PERDA DE SOLO EM PARCELAS DE EROSÃO, SOB DIFERENTES CULTURAS E TÉCNICAS DE MANEJO E A ANÁLISE DE ESTRATÉGIAS DE CONSERVAÇÃO
}

\author{
Helder Lages Jardim $^{(a)}$, Nelson Ferreira Fernandes ${ }^{(b)}$, ndréa Paula de Souza ${ }^{(c)}$ \\ (a) Professor Adjunto do Departamento de Geografia do Instituto de Geociências da Universidade Federal de Minas \\ Gerais - hljardim@gmail.com. \\ (b) Professor Associado do Departamento de Geografia do Instituto de Geociências da Universidade Federal do Rio \\ de Janeiro - nelsonff@uol.com.br \\ (c) Professora Assistente da Faculdade de Educação da Baixada Fluminense- Universidade do Estado do Rio de \\ Janeiro - andreaps0307@hotmail.com
}

EIXO: SOLOS E PAISAGENS

\begin{abstract}
Resumo:
As práticas agrícolas, muitas vezes realizada de forma inadequada, tem acelerado os processos de erosão principalmente em áreas de relevo montanhoso, trazendo graves consequências ambientais e reduzindo a produtividade agrícola e a perda de grandes áreas agriculturáveis. Este trabalho objetiva contribuir para um melhor entendimento da erosão em áreas agrícolas em regiões tropicais úmidas, sob diferentes tipos de manejo e uso, através do monitoramento da perda de solo em quatro parcelas de erosão do tipo Wischmeier: (i) parcela sem presença de cobertura vegetal (SC); (ii) sistema de plantio convencional (PC); (iii) sistema com plantio em nível (PN); (iv) sistema de cultivo mínimo/plantio direto (PD). A parcela SC foi a que apresentou os maiores índices de erosão, com uma média de 20,76 ton/ha para uma chuva média de 20,9mm. A segunda maior perda média foi verificada na parcela PC, com 0,00642 ton/ha para uma chuva média de 18,2mm, seguido da parcela PN com 0,00543 ton/ha para uma chuva média de $18,5 \mathrm{~mm}$ e, por último, a parcela PD com uma perda de 0,00139 ton/ha para uma chuva média de 18,2mm. Estes índices são de suma importância, pois demonstram os riscos de se manter o solo desprotegido de cobertura vegetal em áreas agrícolas de acentuado declive e chuvas intensas da estação chuvosa. Um outro fato que chama a atenção é que dentre as parcelas que receberam algum tipo de conservação, o praticado na região de Paty do Alferes/RJ, a parcela PC (trator morro abaixo e plantio em nível), é o que apresenta os maiores índices de erosão, e os efeitos de assoreamento dos cursos d'água e abandono das terras por perda de produtividade já se fazem sentir. A eficiência das técnicas de conservação do solo para a área ficaram em torno de $99 \%$ em relação à parcela sem plantio.
\end{abstract}

Palavras chave: Erosão do solo, parcelas de erosão, Plantio mínimo, Paty do Alferes

\section{Introdução}

A degradação do solo por meio de processos de erosão é um grave problema nas terras agrícolas pois pode ter consequências espaciais mais amplas do que a própria encosta na qual a erosão ocorre, como a perda de solos férteis e o assoreamento de cursos de água (DUNNE e LEOPOLD, 1978). Assim sendo, a erosão do solo é um fator que pode afetar toda a sociedade, tornando-se um problema cuja magnitude é difícil de se compreender (D'AGOSTINI, 1999). 
Progressos têm sido alcançados na determinação da intensidade da erosão de muitos solos sob grande variação climática, mostrando que as medidas de conservação reduzem a erosão, mas raramente a eliminam completamente (BERTONI e LOMBARDI NETO, 1999). Assim, o problema a decidir então é o quanto de erosão é permissível ou tolerável, levando-se em conta a geomorfologia, a climatologia, a espécie plantada, dentre outros aspectos (FERNANDES, 1996).

Assim, tem-se como objetivos principais do trabalho, o de (i) analisar os efeitos de cobertura do solo e das técnicas de manejo na magnitude, bem como a eficiência das medidas conservacionistas no processo de erosão.

\section{Materiais e métodos}

\section{1. Área de estudo}

A área de estudo está localizada no município de Paty do Alferes, região centro-sul fluminense, na vertente continental da Serra do Mar. Avelar, onde se situa a PESAGRO, local dos experimentos, está localizado nas coordenadas de $22^{\circ} 21^{\prime} \mathrm{S}$ e $43^{\circ} 25^{\prime} \mathrm{O}$ (Figura 1).

O relevo é acidentado, com declividades variando entre $20 \%$ e $45 \%$ e, em alguns trechos, ultrapassando os $45 \%$, onde as terras apresentam um altíssimo grau de susceptibilidade à erosão. Devido às altas declividades, o relevo não permite a utilização de maquinário agrícola em quase sua totalidade (DESUSMO, 1998), onde o principal sistema de preparo do solo é a aração morro abaixo, sem a aplicação de prática conservacionista, além do uso abusivo e indiscriminado de agroquímicos que contribuem para alterar o equilíbrio do agrossistema (BERTOLINO, 2004).

Apresenta um clima do tipo $\mathrm{Cw}$ (Köppen), com temperatura média anual de $20,7^{\circ} \mathrm{C}$, variando entre $24^{\circ} \mathrm{C}$ (fevereiro) e $16,5^{\circ} \mathrm{C}$ (julho). Com relação ao regime pluviométrico, a precipitação média anual gira em trono de $1.159,13 \mathrm{~mm}$, sento concentrada no período entre novembro a janeiro (49,16\% da chuva anual). Já o trimestre mais seco, vai de junho a agosto, com 5,5\% da chuva anual (MARQUES e PINHEIRO, 1998). Os solos da região, apesar de pouca diferenciação no material de origem, possui uma grande variedade de classes, o que confere grande variabilidade na paisagem. Em geral, são argilosos (argila de baixa intensidade), bem drenados, de baixa fertilidade natural com varia espessura do sólum e, que apresentam elevada susceptibilidade à erosão. Na área das parcelas de erosão (figura 2) há o predomínio do Latossolo Vermelho Amarelo.

Com relação ao solo na encosta das parcelas, a parcela de Cultivo Mínimo (PD - aqui chamado de Plantio Direto) foi a que apresentou maior teor de carbono orgânico e, consequentemente, as maiores taxas de infiltração, em oposição à parcela sem cobertura (SC), que obteve as maiores taxas de erosão 


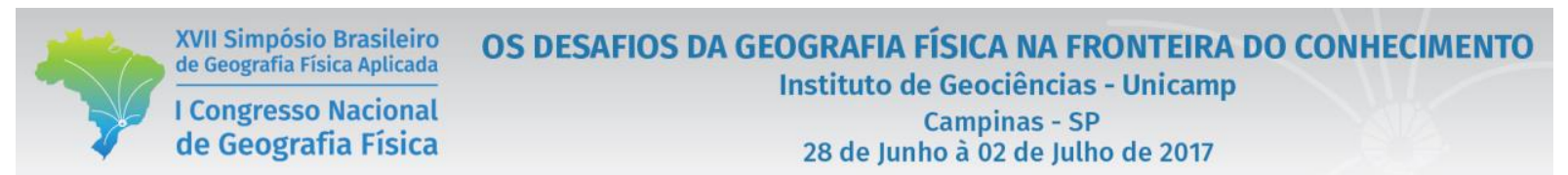

(BERTOLINO, 2004). Na média, as perdas de solo foram menores em CM e PN (Plantio em Nível) e, em relação à perda de água, não foram encontradas diferenças entre os tratamentos (PINHEIRO, 2002).

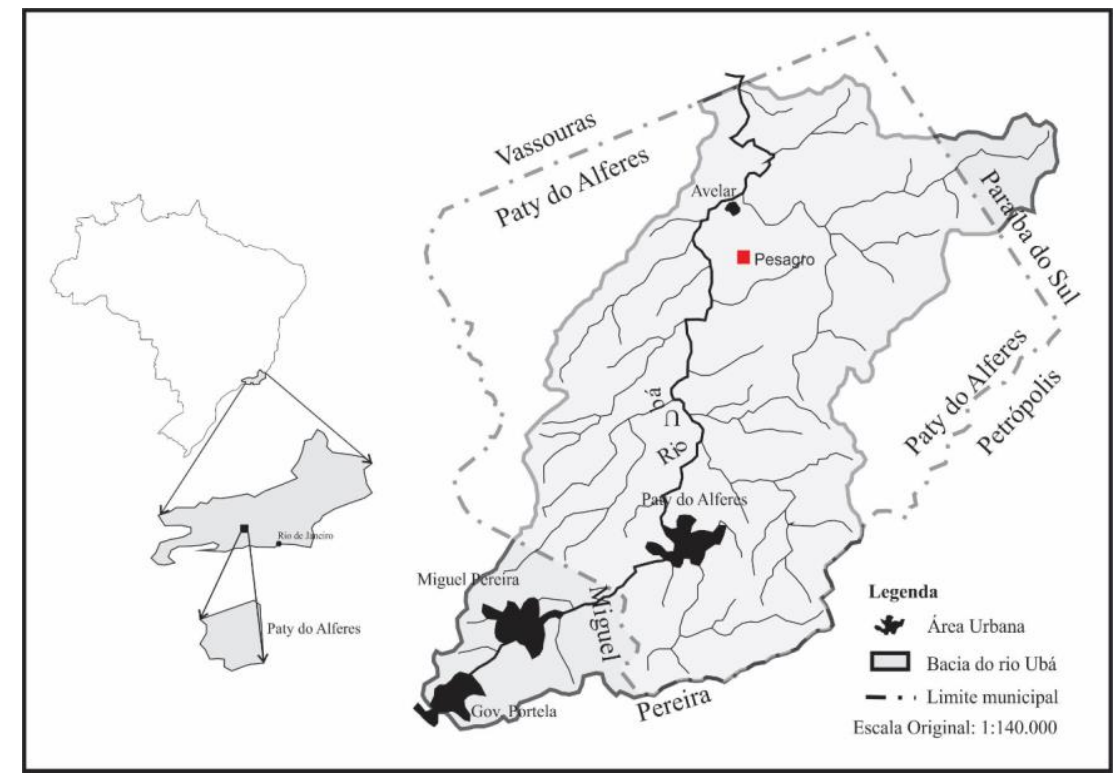

Figura 1: Localização da área de estudos. Fonte: Modificado de PALMIERI (1998)

Quanto ao uso da terra, a maior parte (56,2\%) é utilizada como pastagens de baixa qualidade sendo, tendo sido utilizada anteriormente como horticultura intensiva e posteriormente abandonadas devido à degradação da terra (CARVALHO JÚNIOR, 1996). À época da coleta de dados, Paty do Alferes ocupava um lugar de destaque como um dos maiores produtores de tomate do país, com cerca de $40 \%$ de todo tomate comercializado no estado do Rio de Janeiro e produzindo também abóbora, pimentão, repolho, vagem, cenoura, jiló e ovos (NUÑEZ et al., 1998).

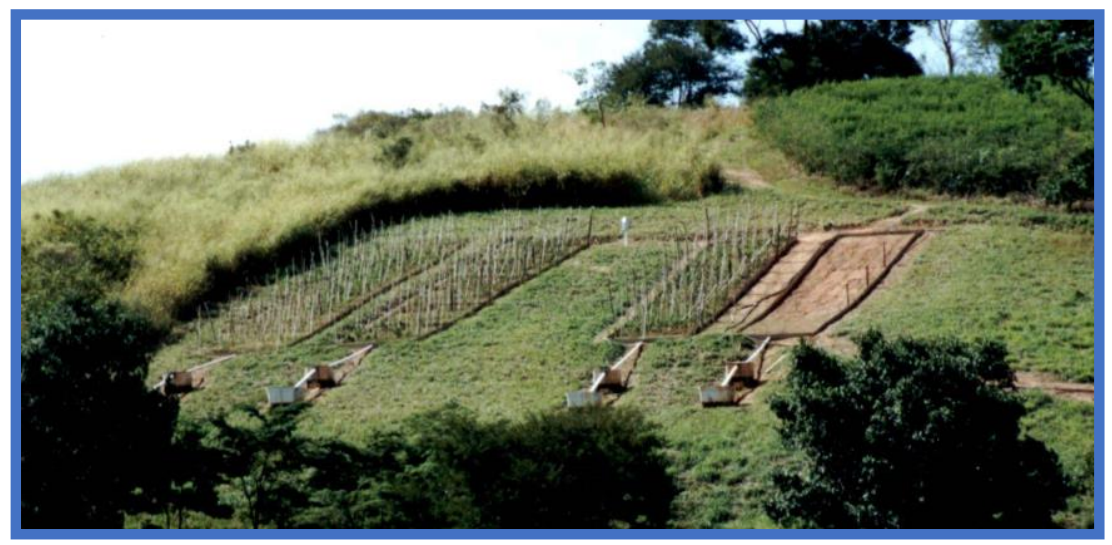

Figura 2: Parcelas de erosão no Campo Experimental da Pesagro - Avelar, Rio de Janeiro, onde foram instaladas as parcelas de erosão do tipo Wischmeier. Da esquerda para a direita, estão as parcelas PD, PN, PC e SC, em uma declividade média de 30\%.Fonte: Jardim, H.L. (2006) 
Entretanto o manejo inadequado das terras tem contribuído para a degradação das condições ecológicas regionais e do solo. Em geral, os fazendeiros utilizavam a terra para a horticultura por aproximadamente dois anos, posteriormente deixando-a em pousio por cinco anos, quando é novamente feito o plantio (CARVALHO JÚNIOR, 1996).

O estudo foi desenvolvido em parcelas de erosão do tipo Wischmeier (MEYER E WISCHMEIER, 1969), sendo que cada parcela possui uma dimensão de $22,0 \times 4,0 \mathrm{~m}$, perfazendo um total de $88,0 \mathrm{~m}^{2}$, apresentando um ponto de coleta ao final e dois tanques de 1.000 litros para armazenamento da água das chuvas e de sedimento (figura 2).

\subsection{Método}

Estudos vêm sendo realizados na área desde 1994, mais especificamente nas bacias dos rios Saco e Ubá (fig. 01). Neste trabalho foram utilizados dados obtidos através de parcelas de erosão coletados por TURETTA (2000), BERTOLINO (2004), SOUZA (2004) e por monitoramento realizado por JARDIM (2004). Neste período foram cultivados por estes autores, principalmente o pepino, tomate, feijão de vagem, couve e pimentão.

Foram instaladas 4 parcelas de erosão do tipo Wischmeier a meia encosta, com $30 \%$ de declividade e dimensão de 22,0 x 4,0 metros:

- Parcela Sem Cultivo - SC: sistema sem presença de cobertura vegetal, com utilização de arado de disco com trator e sem irrigação, de modo a simular as condições de erosão no período de entressafra ${ }^{1}$;

- Parcela de Plantio Convencional - PC: sistema de preparo convencional, com utilização de queimada, arado com trator morro abaixo e irrigação por molhamento;

- Parcela de Plantio em Nível - PN: sistema sem utilização de queimada, arada com junta de boi e plantação em nível com irrigação por molhamento. A cada 6 metros, foi plantada uma faixa de gramínea (capim Colonião), de modo a tentar diminuir a movimentação de sedimentos pela parcela durante os eventos chuvosos;

- Parcela de Plantio Mínimo - PD: sistema de cultivo mínimo/plantio direto, com irrigação por molhamento.

\footnotetext{
${ }^{1}$ No interstício de 2001 a 2004 esta parcela permaneceu sem tratamento.
} 
Os dados de erosão foram levados ao laboratório para serem processados segundo metodologia recomendada pela EMBRAPA/CNPS (1997) e posteriormente foi calculada a perda de solo para cada parcela individualmente, através da fórmula:

$$
\text { PERDA }=\left(\left(\frac{P A-P B}{V A}\right) * V E\right) / 1000
$$

Onde $P A$ é o peso da amostra seca, $P B$ é o peso do Becker, $V A$ é o volume total da amostra e $V E$ é o volume do escoamento, sendo calculado individualmente para cada parcela de erosão (SC, PC, PN e PD) e para cada evento chuvoso.

Para o monitoramento das parcelas de erosão neste trabalho, foram utilizados dois tipos de cultivos comumente utilizados em Paty do Alferes: Pimentão (Capsicum annuum) e feijão de vagem (Phaseolus vulgaris), como pode ser observado na tabela I.

Para mensuração da erosão, registros pluviométricos foram obtidos registros diários através de pluviômetros e outros equipamentos no Campo Experimental da Pesagro, em Avelar, com dados de chuva remontando ao ano de 1971. Estes registros auxiliaram no entendimento da distribuição e representatividade das chuvas no processo de erosão nas parcelas. A partir de 1995, além dos dados da estação climática da Pesagro/Rio, também foi instalado um pluviógrafo de registro contínuo próximo às parcelas.

Tabela I: Culturas utilizadas nas parcelas de erosão.

\begin{tabular}{|c|c|c|}
\hline & Período & Cultura \\
\hline \multirow{3}{*}{1} & De 06 de novembro de 2000 a 23 de março de 2001 & Pimentão \\
\hline & De 24 de março a 18 de junho de 2001 & Solo com restos culturais \\
\hline & De 19 de junho a 28 de setembro de 2001 , & Solo sem restos culturais \\
\hline \multirow{3}{*}{2} & 29 de agosto de 2001 a 22 de novembro de 2001 & Feijão \\
\hline & De 23 de novembro de 2001 a 15 de dezembro & Solo com restos culturais \\
\hline & De 16 a 19 de novembro de 2001 & Solo sem restos culturais \\
\hline \multirow{3}{*}{3} & De 19 de dezembro de 2001 a 28 de maio de 2002 & Pimentão \\
\hline & De 29 de maio a 15 de julho de 2002 & Solo com restos culturais \\
\hline & De 16 de julho a 16 de novembro & Solo sem restos culturais \\
\hline \multirow{3}{*}{4} & 17 de novembro de 2002 a 09 de fevereiro de 2003 & Feijão \\
\hline & De 10 de fevereiro a 19 de fevereiro de 2003 & Solo com restos culturais \\
\hline & De 20 de fevereiro a 03 de dezembro de 2003 & Solo sem restos culturais \\
\hline \multirow{2}{*}{5} & 04 de dezembro de 2003 a 27 de fevereiro de 2004 & Feijão \\
\hline & De 27 de fevereiro a 02 de abril de 2004 & Solo com restos culturais \\
\hline
\end{tabular}


XVII Simpósio Brasileiro

de Geografia Fisica Aplicada

I Congresso Nacional

de Geografia Física

A partir de 03 de abril
OS DESAFIOS DA GEOGRAFIA FÍSICA NA FRONTEIRA DO CONHECIMENTO

Instituto de Geociências - Unicamp

Campinas - SP

28 de Junho à 02 de Julho de 2017

Solo sem restos culturais

Fonte: Jardim, H.L. (2006).

Através dos dados do pluviógrafo foram calculados o coeficiente de chuva $(R C)$ e o $\mathrm{EI}_{30}$ através da seguinte expressão:

$$
R c=P_{m}^{2} / P_{a}
$$

Onde $R c$ é o coeficiente de chuva em $\mathrm{mm}, P m$ a precipitação média mensal em $\mathrm{mm}$ e $P a$ a precipitação média anual. $\mathrm{E}$ o $E I_{30}$ foi calculado a partir da expressão:

$$
E I_{30}=67,414 * R_{c}^{0,850} \quad(\mathrm{r}=0,991)
$$

Onde $E I_{30}$ é a estimativa do índice de erosividade médio mensal em MJ.mm/ha.h e $r$ é o coeficiente de correlação.

Foram também cruzados os dados de erosão, cobertura vegetal e manejo e estabelecido pesos a cada uma destas fases, referentes à proteção exercida pela planta, sobre o solo. O período de cada cultura foi subdividido de acordo com as fases do plantio, de modo a tentar estimar para cada fase, a proteção exercida pela cultura sobre o solo, sendo assim divididas: $(i)$ plantio/emergência; (ii) maturação (fase 1); (iii) maturação (fase 2); (iv) florada/colheita e; (v) pós colheita. A fase de plantio/emergência foi estabelecida em campo, cuja duração vai do plantio da semente até a planta atingir cerca de $15 \mathrm{~cm}$ de caule, estabelecendo-se um máximo de $10 \%$ de proteção sobre o solo ${ }^{2}$. A fase de maturação é definida como o crescimento vegetativo que inicia na emergência (após o término da fase de plantio/emergência) e vai até o dia da florada, durando cerca de 52 dias para a cultura do pimentão e de 34 dias para a do feijão e foi dividida em duas fazes de períodos iguais (tabela II).

Já na fase florada/colheita, a planta atinge seu pleno desenvolvimento, alcançando cerca de $100 \%$ da proteção esperada por cada cultivo, estabelecendo-se então um fator de peso igual a 10. Na fase de pós colheita, este fator foi reduzido em $10 \%$ (fator $=9$ ) devido à permanência dos restos culturais sobre as parcelas.

Para cada tipo de manejo, foi também estabelecido um peso. Assim, atribuiu-se o peso 3 para o Plantio Direto - PD, por proteger mais o solo; o peso 2 para o Plantio em Nível - PN e; o peso 1 para o Plantio Convencional - PC.

Tabela II: Cronograma e pesos atribuídos a cada fase de desenvolvimento das culturas.

\begin{tabular}{lllllll}
\hline Cultura & \multirow{2}{*}{ Ação } & \multirow{2}{*}{ Período } & Observações & $\begin{array}{l}\text { Peso } \\
\text { Cobertura }\end{array}$ & $\begin{array}{l}\text { Peso do } \\
\text { Manejo }\end{array}$ & $\begin{array}{l}\text { Manejo } x \\
\text { Cobertura }\end{array}$ \\
\hline
\end{tabular}

${ }^{2}$ Para o caso da parcela PD (Plantio Direto), o fator de proteção foi dobrado, tendo em vista que os restos do cultivo anterior permaneceram na parcela. 


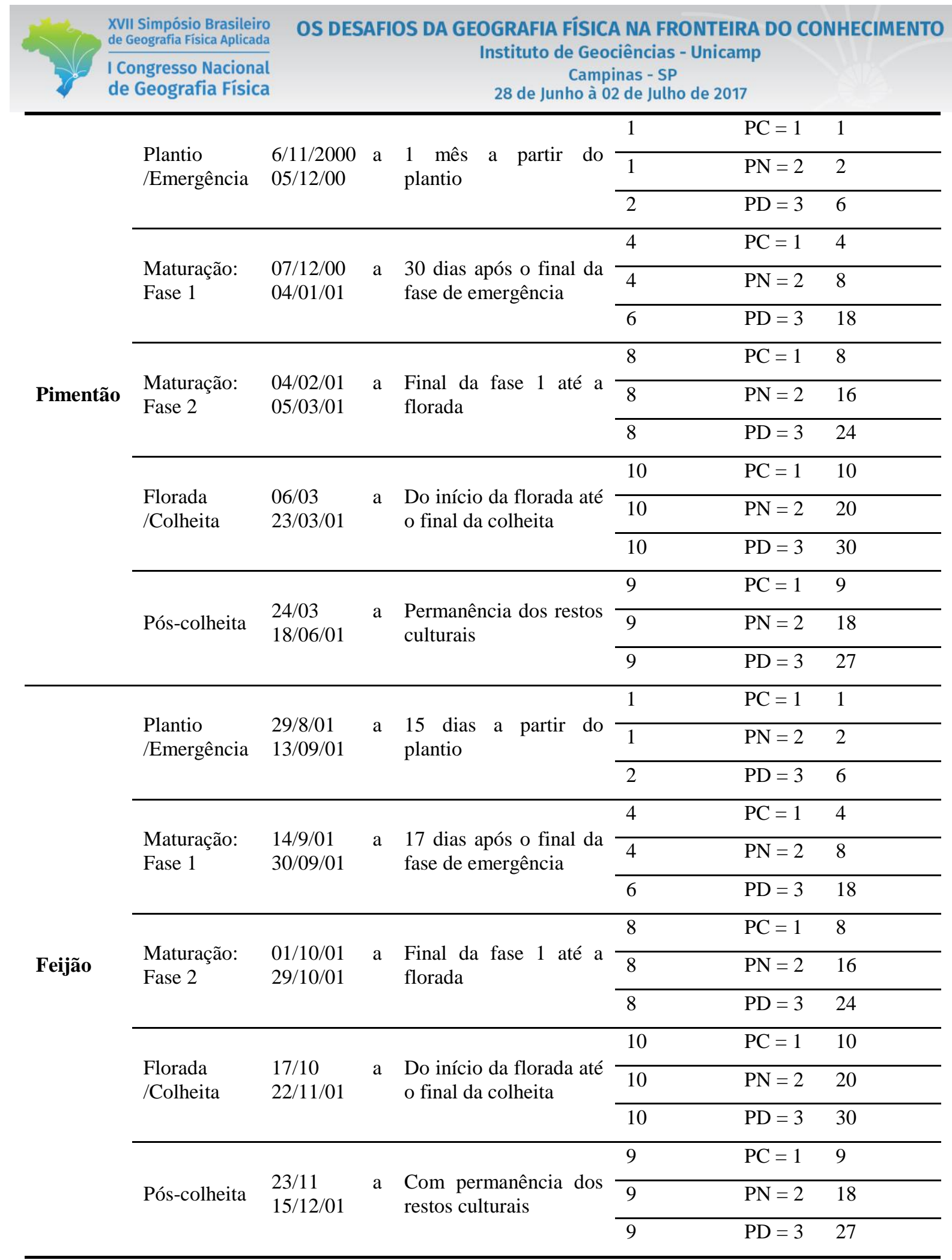

A partir de então, os fatores de Peso da Cobertura e Peso do Manejo foram multiplicados de modo a estabelecer a correlação entre a perda de solo e os fatores de manejo e cobertura presentes em cada parcela. 


\section{Resultados}

Com relação aos dados de chuva, o mês de janeiro é o que apresenta a maior concentração das chuvas anuais, contribuindo, na média, com $18,5 \%$ da chuva média anual e $41,16 \%$ do trimestre mais chuvoso, como pode-se observar pela tabela III. O período de novembro a janeiro apresentam os maiores coeficientes de chuva, alcançando 16,98mm, 39,95mm e 40,71mm, respectivamente. Esta é normalmente a estação onde o solo é preparado, dando início aos cultivos da região, devido à abundância de água e temperaturas mais amenas. Entretanto, esta época apresenta-se com o maior $\mathrm{EI}_{30}(748,51 ; 1548,96 \mathrm{e}$ 1573,97MJ.mm/ha.h, respectivamente para os meses de novembro, dezembro e janeiro), fazendo com que as chuvas tenham o maior poder de erosão o que, pode ser intensificado devido à falta de cobertura vegetal e ao relevo acidentado.

Já o trimestre mais seco, que vai de junho a agosto, contribui com somente 5,5\% da chuva anual em Paty do Alferes. Neste período, o mês de agosto foi o que mostrou a maior variação dos dados, sendo que para os anos de 2002 e 2003 os valores pluviométricos estiveram muito acima da média, se comparado a anos anteriores.

Tabela III: Chuva em paty do Alferes - Totais mensais, anuais, índice de chuva (Rc) e $\mathrm{EI}_{30}$.

\begin{tabular}{|c|c|c|c|c|c|c|c|c|c|c|c|c|c|}
\hline & $\begin{array}{l}\text { JAN } \\
(\mathbf{m m})\end{array}$ & $\begin{array}{l}\text { FEV } \\
(\mathbf{m m})\end{array}$ & $\begin{array}{l}\text { MAR } \\
(\mathbf{m m})\end{array}$ & $\begin{array}{l}\text { ABR } \\
(\mathbf{m m})\end{array}$ & $\begin{array}{l}\text { MAI } \\
(\mathbf{m m})\end{array}$ & $\begin{array}{l}\text { JUN } \\
(\mathbf{m m})\end{array}$ & $\begin{array}{l}\text { JUL } \\
(\mathbf{m m})\end{array}$ & $\begin{array}{l}\text { AGO } \\
(\mathbf{m m})\end{array}$ & $\begin{array}{l}\text { SET } \\
(\mathbf{m m})\end{array}$ & $\begin{array}{l}\text { OUT } \\
(\mathbf{m m})\end{array}$ & $\begin{array}{l}\text { NOV } \\
(\mathbf{m m})\end{array}$ & $\begin{array}{l}\text { DEZ } \\
(\mathbf{m m})\end{array}$ & $\begin{array}{l}\text { TOTAL } \\
\text { ANUAL } \\
(\mathbf{m m})\end{array}$ \\
\hline $\mathbf{2 0 0 1}$ & 139,8 & 94,8 & 340,2 & 36,7 & 48,0 & 0,0 & 0,0 & 14,9 & 25,3 & 65,2 & 152,9 & 304,6 & 1222,4 \\
\hline $\mathbf{2 0 0 2}$ & 140,3 & 94,4 & 93,7 & 11,0 & 63,1 & 0,0 & 25,7 & 33,8 & 96,5 & 78,7 & 143,0 & 278,1 & 1058,3 \\
\hline $\mathbf{2 0 0 3}$ & 403,3 & 94,6 & 129,3 & 36,6 & 18,1 & 0,2 & 8,7 & 42,0 & 28,5 & 159,3 & 204,8 & 101,5 & 1226,9 \\
\hline Média & $214,34^{3}$ & 124,44 & 132,84 & 64,17 & 44,97 & 23,79 & 18,18 & 21,78 & 63,62 & 92,64 & 140,30 & 215,18 & 1159,13 \\
\hline C.M. (\%) & 18,5 & 10,7 & 11,5 & 5,5 & 3,9 & 2,1 & 1,6 & 1,9 & 5,5 & 8,0 & 12,2 & 18,6 & 100,0 \\
\hline Rc (mm) & 40,71 & 13,36 & 15,22 & 3,55 & 1,74 & 0,49 & 0,29 & 0,41 & 3,49 & 7,40 & 16,98 & 39,95 & \\
\hline EI30 & 1573,97 & 610,50 & 682,03 & 197,90 & 107,95 & 36,76 & 23,54 & 31,59 & 195,05 & 369,49 & 748,51 & 1548,96 & \\
\hline
\end{tabular}

C.M.: Contribuição média da chuva em \%; Rc: Coeficiente de chuva. Fonte: Adaptação dos dados meteorológicos da Estação Meteorológica de PESAGRO/Avelar - Paty do Alferes, RJ.

Quando se compara o aumento do volume das chuvas com a erosão medida, observa-se que há uma correlação positiva, com uma tendência do aumento da erosão do solo com crescimento dos volumes pluviométricos (tabela IV). Já a relação do aumento da erosão com a intensidade da chuva, apresenta uma

\footnotetext{
${ }^{3}$ Este valor leva em consideração o mês de janeiro de 2004 que teve um total de chuva de 119,3mm.
} 
correlação positiva inferior, se comparado aos totais pluviométricos, muito provavelmente devido ao crescimento das culturas plantadas e sua respectiva proteção do solo.

Já a parcela SC, de referência da erosão máxima possível, apresentou a maior correlação entre os dados, pois não houve variação em sua cobertura durante o período analisado.

Com relação à perda de solo nas parcelas, a parcela SC - Sem Cobertura foi a que apresentou os maiores índices de erosão, com uma perda média de 20,76ton/ha por evento, enquanto que nas outras a perda média de solo por evento foi de 0,006 ton/ha.

Tabela IV: Média, desvio padrão e correlação entre perda de solo e chuva nas parcelas SC, PC, PN e PD.

\begin{tabular}{ccccccccc}
\hline & \multicolumn{2}{c}{ PARCELA SC } & \multicolumn{2}{c}{ PARCELA PC } & \multicolumn{2}{c}{ PARCELA PN } & \multicolumn{2}{c}{ PARCELA PD } \\
\cline { 2 - 9 } & $\begin{array}{c}\text { Perda } \\
(\text { ton/ha) }\end{array}$ & $\begin{array}{c}\text { Chuva } \\
(\mathbf{m m})\end{array}$ & $\begin{array}{c}\text { Perda } \\
(\mathbf{t o n} / \mathbf{h a})\end{array}$ & $\begin{array}{c}\text { Chuva } \\
(\mathbf{m m})\end{array}$ & $\begin{array}{c}\text { Perda } \\
(\text { ton/ha) }\end{array}$ & $\begin{array}{c}\text { Chuva } \\
(\mathbf{m m})\end{array}$ & $\begin{array}{c}\text { Perda } \\
(\text { ton/ha) }\end{array}$ & $\begin{array}{c}\text { Chuva } \\
(\mathbf{m m})\end{array}$ \\
\hline Média & 20,76 & 20,9 & 0,00642 & 18,2 & 0,00543 & 18,5 & 0,00139 & 18,2 \\
\hline Desvio Padrão & 16,35 & 15,84 & 0,00459 & 21,8 & 0,00329 & 20,9 & 0,00112 & 21,6 \\
\hline $\begin{array}{c}\text { Correlação } \\
\text { Perda x Totais de } \\
\text { chuva (r) }\end{array}$ & 0,60918 & 0,53192 & 0,52116 & 0,48486 \\
\hline $\begin{array}{c}\text { Correlação } \\
\text { Perda x } \\
\text { Intensidade (r) }\end{array}$ & 0,26582 & 0,37671 & 0,26369 & & 0,54728 \\
\hline
\end{tabular}

A parcela PC - Plantio Convencional, onde o solo é preparado com a utilização de queimada dos restos da cultura anterior, arado com trator morro abaixo e plantio em nível foi a que apresentou a maior perda média de solo entre as parcelas cultivadas (PC, PN e PD). Isto é um indicativo de que o plantio convencional difundido em Paty do Alferes (RJ), aliado às altas declividades e ao regime pluviométrico da região não é o mais adequado pois, muitas vezes, se traduz em prejuízo aos agricultores que costumam perder suas lavouras nos eventos chuvosos mais intensos. A perda média de solo nesta parcela foi de 0,00459ton/ha, apresentando uma redução média de 99,99\% em relação à parcela SC. Entretanto, dentre as parcelas cultivadas, esta foi a que apresentou os maiores índices de erosão. Isto corrobora o fato de as terras plantadas na região possuírem um tempo de produção muito baixo, sendo abandonadas em poucos anos e transformadas em pastagens. Isto também impactou a produção em Paty do Alferes que num prazo de pouco mais de 4 anos (alvo direto do monitoramento aqui realizado) perdeu em muito sua posição no ranking do estado do Rio de Janeiro em relação à produção de tomate (e outras olerículas), apesar de, em princípio, apresentar os maiores índices em produtividade, com uma média de $86 \mathrm{~kg}$ para o cultivo de feijão e de $123,2 \mathrm{~kg}$ para o cultivo do pimentão, como pode ser observado na tabela $\mathrm{V}$. 
Tabela V: Produtividade das culturas da couve-flor, pimentão e feijão de vagem nas parcelas PC, PN e PD.

\begin{tabular}{|c|c|c|c|c|c|c|}
\hline \multirow{3}{*}{ PRODUTO } & \multicolumn{6}{|c|}{ PRODUÇÃO NAS PARCELAS DE EROSÃO } \\
\hline & \multicolumn{2}{|l|}{$\mathbf{P C}$} & \multicolumn{2}{|l|}{ PN } & \multicolumn{2}{|l|}{ PD } \\
\hline & (kg) & $\%$ & (kg) & $\%$ & (kg) & $\%$ \\
\hline Feijão $^{4}$ & 86,8 & 100 & 80,4 & 92,63 & 75,7 & 87,21 \\
\hline Pimentão $^{5}$ & 123,2 & 100 & 117,5 & 95,37 & 94,2 & 76,46 \\
\hline
\end{tabular}

A parcela de Plantio em Nível - PN apresentou índices intermediários de erosão (quando comparada às parcelas PC e PD), com uma média de 0,00230 ton/ha, para uma chuva média de $20,9 \mathrm{~mm}$. Isto pode ser atribuído em parte à presença de uma faixa de capim colonião, de $3 \mathrm{em} 3 \mathrm{~m}$ ao longo da parcela, que reteve a maior parte dos sedimentos, impedindo-os de chegar aos tanques de coleta. O modo de preparo, utilizando um arado com tração animal e em nível, promoveu uma menor compactação do solo sem a criação de caminhos preferenciais à circulação de água como no plantio convencional. Entretanto, a produtividade desta parcela foi inferior à contabilizada na parcela PC, com 80,4kg, perfazendo 92,63\% da produtividade do plantio convencional da região.

Já a parcela de Plantio Direto - PD apresentou os menores índices de perda de solo, com 0,00112kg/ha e as menores taxas de escoamento superficial. Este fato é um sinal de que, após aproximadamente dez anos sendo cultivada, a cobertura vegetal pode ter melhorado as características físicas do solo, tais como o aumento da porosidade total, como atesta BERTOLINO (2004). Para a autora, a profundidade de $0-11 \mathrm{~cm}$ apresenta uma estrutura granular e uma porosidade elevada com macroporos conectados de vários tamanhos. Na profundidade de $11-22 \mathrm{~cm}$, o plantio direto apresentou a maior porosidade entre todos os sistemas, com uma estrutura em blocos de fraca a moderada. Já para a profundidade de $25-36 \mathrm{~cm}$, houve a presença mista de blocos e granular com cavidades interconectadas. Os sistemas de plantio direto e convencional apresentaram também estruturas distintas, o que refletiu no comportamento hidrológico das duas parcelas. Com relação à produtividade desta parcela para os cultivos de pimentão e feijão, esta foi a que apresentou os menores índices, com $75,7 \mathrm{~kg}$ de produção para a cultura do feijão e de $94,2 \mathrm{~kg}$ para o pimentão. Isto perfaz respectivamente, $87,21 \%$ e $76,46 \%$ de produtividade da parcela PC. Entretanto esta baixa produtividade em relação às outras parcelas pode ter como origem o próprio tipo de manejo, onde a adubação era jogada sobre as covas, sem revolvimento, o que melhoraria sua incorporação às camadas

${ }^{4}$ Colheita iniciada em 29/10/01 e finalizada em 22/11/01.

${ }^{5}$ Colheita iniciada em 19/03/02 e finalizada em 28/05/02. 
superficiais do solo. Desde que foi criado, a parcela PD vem se consolidando em termos de produtividade, que tem aumentado ao longo do tempo, passando de 48,6\% nos primeiro cultivos para $76,46 \%$ (pimentão) em relação à parcela PC. Daí se conclui que, apesar da baixa produtividade inicial, ao longo do tempo o plantio direto se consolida com a melhora da produtividade, como consequência da melhora das características físicas do solo, principalmente a porosidade e fortalecimento dos agregados superficiais.

\section{Considerações finais}

O monitoramento da perda de solo em áreas agrícolas através de parcelas de erosão do tipo Wischmeier na Estação Experimental da Pesagro em Paty do Alferes/RJ revelou aspectos importantes sobre a dinâmica agrícola da região.

Com relação ao regime pluviométrico nos anos aqui analisados (2001 a 2003), as médias pluviométricas não apresentaram grande variação. Entretanto, ao se analisar individualmente foi percebido que os meses de novembro de 2003 se caracterizou como extremamente chuvoso, assim como o mês de dezembro de 2001 e $2002^{6}$.

Quando se fez a correlação entre os totais de chuva e a perda de solo nas parcelas, observou-se o maior índice, mesmo que baixo, para a parcela SC, devido ao fato desta não ter sido cultivada e não haver variação em sua cobertura. Já para as parcelas PC e PN, as menores correlações podem ser oriundas da grande variação da cobertura vegetal ao longo do crescimento do cultivo.

No que se refere à perda de solo, observou-se que as quantidades de solo perdidas na parcela SC foram muito superiores às outras parcelas. Este fato demonstra que, devido às altas declividades presentes na área (30\%), aliado à friabilidade dos latossolos, além da concentração das chuvas nos meses de novembro a janeiro, podem desencadear processos de erosão, provocando grandes perdas para a agricultura local.

Dentre os tratamentos testados (PC, PN e PD), o plantio direto foi o que apresentou uma maior eficiência no controle da perda de solo, principalmente devido ao não revolvimento da terra durante o preparo para o plantio, bem como à cobertura morta sempre presente sobre o solo. Entretanto, foi o que apresentou a princípio os menores índices de produtividade, mas que foi crescendo ao longo dos anos (era 48,6\% inferior ao plantio convencional em 2000 e passou para 33,54\% em 2002).

A maior produtividade sempre foi ao do plantio convencional, mas vale ressaltar que em médio e longo prazos, esta produtividade vem caindo e degradando o solo de tal maneira que em poucos anos só resta ao produtor abandonar a gleba e dar outro uso, como a pastagem, como vem ocorrendo na região.

${ }^{6}$ Somente no dia 26/12/2002, ocorreu uma chuva de $147 \mathrm{~mm}$ com duração de $8 \mathrm{~h}$, perfazendo uma intensidade de $18,38 \mathrm{~mm} / \mathrm{h}$. 


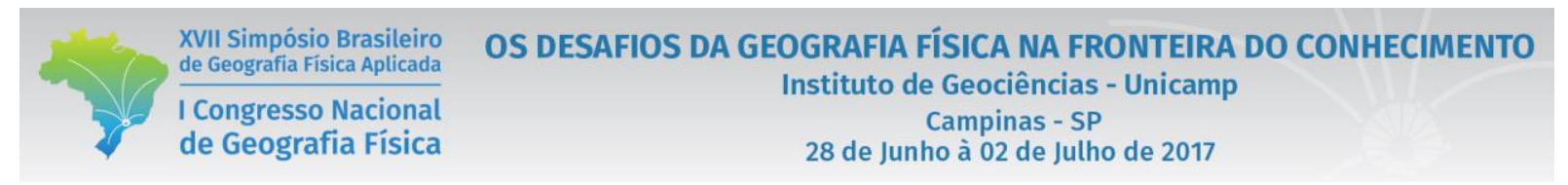

\section{Referências Bibliográficas}

BERTOLINO, A.V.F.B. Monitoramento dos fluxos de água no solo sob diferentes tipos de manejo e uso - Estação experimental de Avelar (Paty do Alferes). (Tese de Doutorado em Geografia Física), UFRJ, Rio de Janeiro. 2004.

BERTONI, J.; LOMBARDI NETO, F. Conservação do solo. Ed. Ícone, São Paulo, 1999. 355p.

CARVALHO JÚNIOR, W. Modelos de planejamento agrícola conservacionista com suporte de geoprocessamento estudo de caso nos municípios de paty do Alferes e Miguel Pereira - RJ, Dissertação de Mestrado, Instituto de Geociências, Universidade Federa do Rio de Janeiro, Rio de Janeiro. 1996.

D'AGOSTINI, L. R. Erosão: o problema mais que o processo. Editora da UFSC, Florianópolis, 1999, 131p.

DESUSMO. Development of sustainable farming systems on mountainous low fertility grazing land in South America. Commition of the Europe communities, R\&D Programme "Life sciences and technologies for developing countries". 1997. 165p.

DUNE, T.; LEOPOLD, L. Water in environmental planning. W. H. Freeman, New York, 1978. 818p.

EMBRAPA/CNPS. Manual de métodos de análise de solos. Rio de Janeiro, 1997. 212p.

FERNANDES, N. F. Modelagem matemática em geomorfologia: potencialidades e limitações. Sociedade $\boldsymbol{e}$ Natureza. Universidade Federal de Uberlândia, Uberlândia, 1996. p.222-227.

JARDIM, H.L. Estudo da Perda de solo em parcelas de erosão, sob diferentes culturas e técnicas de manejo e anãlise de estratégias de conservação. Tese de Doutorado. UFRJ - Instituto de Geociênciências, julho de 2006.

MARQUES, J.; PINHEIRO, F.M.A. Estudos hidrometeorológicos de Paty do Alferes, RJ: resultados preliminares. Workshop nacional de agricultura sustentável em regiões tropicais de relevo acidentado, 3, Paty do Alferes, RJ: Anais. Rio de Janeiro: EMBRAPA-CNPS, 1998. CD-ROM.

MEYER, I.D.; WISCHMEIER, W.H. Mathematical simulation of the process of soil erosion by water. Trans. of the $\boldsymbol{A S A E}$, St. Joseph, 1969. 12:754-758.

NUÑEZ, J.E.U.; SOBRINHO, N.M.B.; KUNZMANN, M.; PALMIERI, F. Perdas de metais pesados por erosão, influenciado pelo sistema de preparo do solo na microbacia de Caetés, Paty do Alferes. Workshop Nacional de Agricultura Sustentável em Regiões Tropicais de Relevo Acidentado, 3, Paty do alferes, Anais. Rio de Janeiro, EMBRAPA-CNPS, 1998. CD-ROM.

PALMIERI, F. Interações ambientais tendo em vista o desenvolvimento sustentável das microbacias dos afluentes do córrego do Saco-Rio Ubá nos municípios de Paty do Alferes e Miguel Pereira-R.J. Rio de Janeiro. Embrapa-CNPS1998. Tomo I, II e III. 614p. Consórcio Embrapa Solo/UFRJ/UFRRJ/UERJ/ UFF/Fiocruz/INT/EMATERRIO/PMPA. Relatório Final ref. Convênio: 66.96.0078.00. Rel. contratação: 312161096. 1988

PINHEIRO, E. Frações orgânicas e agregação em Latossolo Vermelho em função de sistemas de oleráceas em Paty do Alferes, RJ. Dissertação de Mestrado em Agronomia. Instituto de Agronomia. UFRRJ. Seropédica, 2002. 77p

TURETTA, A.P.D. Alterações edáficas em função do manejo agrícola de oleráceas em latossolo vermelho no bioma mata atlântica - Paty do Alferes, RJ. Tese de Doutorado. UFRRJ - Instituto de Agronomia, março de 2000, 122p. 